
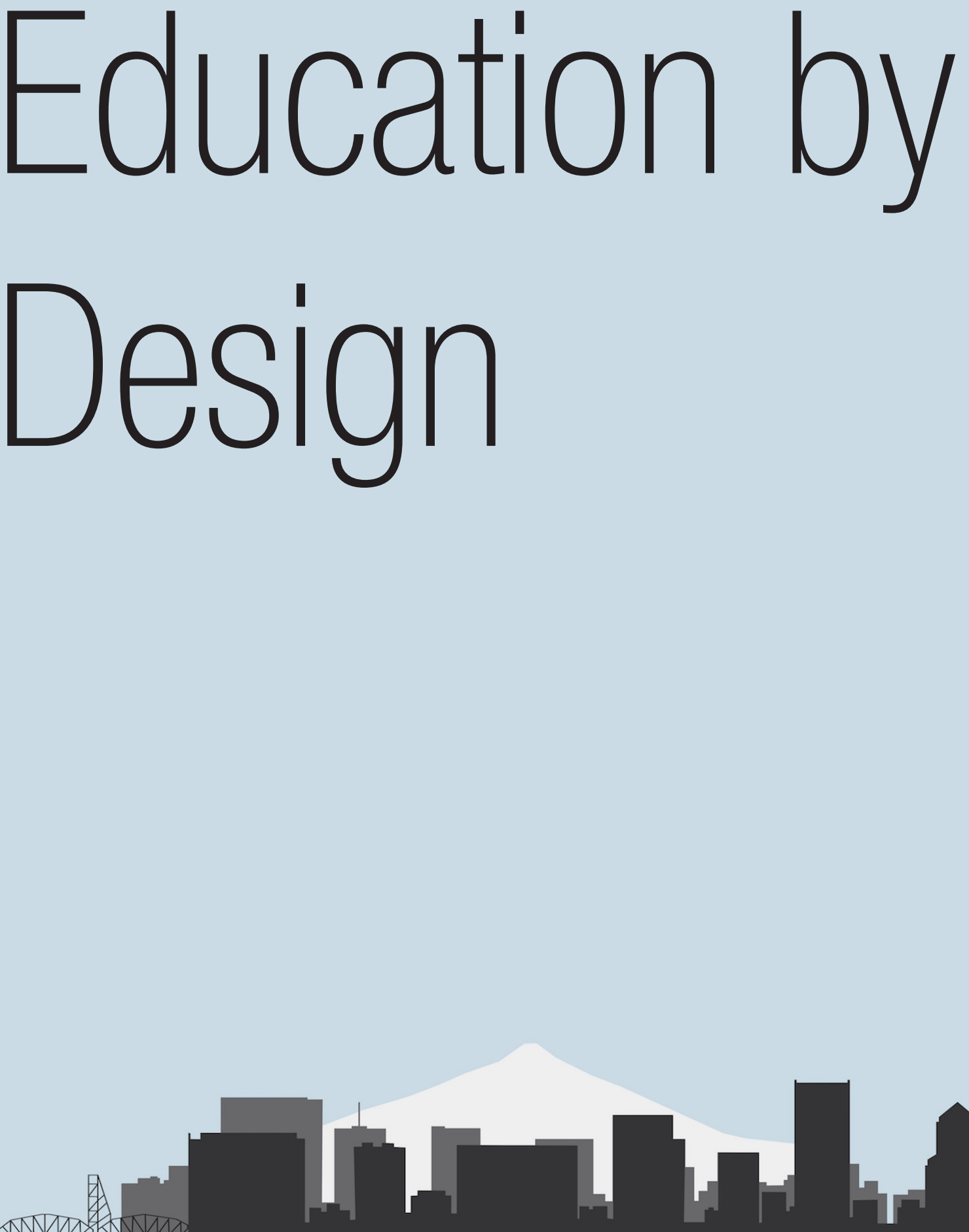

2019 Reynolds Symposium: Education by Design October 18-20, 2019 


\section{Organizing Committee:}

[co-organizers]

Professor Alison Kwok, Ph.D, FAIA, University of Oregon

Emeritus Professor John Reynolds, FAIA, University of Oregon

\section{[Symposium coordinator]}

Isabel Rivera, Ph.D., University of Oregon

Professor Walter Grondzik, P.E., Ball State University

Professor Bruce Haglund, AIA Assoc., University of Idaho

Assistant Professor Emily McGlohn, AIA, Auburn University

Associate Professor Ulrike Passe, lowa State University

Assistant Professor Siobhan Rockcastle, Ph.D., University of Oregon

Sharon Refvem, FAIA, LEED Fellow, Senior Associate and Director, Sustainability Resource Group, Hawley Peterson Snyder 


\title{
Service-Learning Projects in Passive Solar Heating through the Sustainable City Year Program
}

\author{
Alexandra R. Rempel, Ph.D., M.Arch. \\ Assistant Professor \\ University of Oregon \\ Eugene, Oregon \\ arempel@uoregon.edu
}

\author{
Megan Banks, M.C.R.P. \\ Manager, Sustainable City Year Program \\ University of Oregon \\ Eugene, Oregon \\ mbanks@uoregon.edu
}

\begin{abstract}
Service learning engages students with community partners in creating products for public benefit, allowing students to learn field research and design communication methods while contributing their time and expertise. From 2017-19, the University of Oregon Passive Heating Seminar has collaborated with the Sustainable City Year Program to provide schematic passive heating designs to three climatically distinct cities: Mediterranean Albany, sunny semi-arid La Pine, and coastal Dunes City, Oregon. These projects have provided specific sites, motivated clients, and authentic problems to students while promoting passive heating use in realizable, publicly-visible projects. In 2017, the City of Albany requested designs for a senior center sunspace, a community greenhouse, and park restrooms that would allow parks to remain open for events during cooler months. Schematic designs and performance estimates then allowed Albany to begin fundraising for construction. In 2018, the City of La Pine requested designs for a City Center, a community greenhouse, and a balcony sunspace prototype for multifamily housing. The City Center is currently under development, and the balcony sunspace projects supported acquisition of federal funding for further research. Dunes City, in turn, supported by a JPB Foundation grant, worked with students in 2019 to develop passive heating designs for disaster-relief shelters in the event of a catastrophic earthquake and tsunami. Together, these projects have allowed regional leaders to explore and develop their communities' interests in passive solar heating as they strive to create resilient communities, while simultaneously promoting students' awareness of their own potential as designers to support such efforts.
\end{abstract}

\section{INTRODUCTION}

The desires of advanced students for immediate purpose and applicability in their projects, and the needs of communities for imaginative, low-cost expertise, are met well by service-learning projects: those that apply student effort to problems in a way that creates public benefit as well as educational and personal student development (Bringle and Hatcher 2000). Collaborating with community partners encourages students to develop their abilities to listen closely, to ask questions clearly, and to revise their own ideas to integrate partner input. Often, students encounter concerns from their partners regarding feasibility, appropriateness, appearance, cost, etc. that may seem to resist their efforts but that arise from constraints and experiences unfamiliar to the students. Accepting and exploring their collaborators' concerns, incorporating their priorities, and recognizing the influences underlying their own perceptions are regarded as some of the most valuable components of service learning for students (Sletto 2010). In addition, challenges intrinsic to field projects - difficulties presented by actual sites, weather, and instruments; incompleteness or conflicting nature of information provided - develop students' reliance on critical thinking and academic initiative, which help them discern likely truths and make the best estimates possible at the time (Astin et al. 2000; Sedlak et al. 2003).

From the community perspective, in turn, service-learning projects provide forums in which to explore possibilities with greater freedom than might otherwise be possible. Student input is valued for its imagination, idealism, and energy, as well as its graphic quality, and community leaders have reported that student efforts can infuse stalled projects with a new sense of possibility (Blouin and Perry 2009; Sandy and Holland 2006). Service-learning advocates also value the strengthening of shared purpose between universities and nearby communities that can result, writing: “...the academy must become a 
more vigorous partner in the search for answers to our most pressing social, civic, economic, and moral problems, and must reaffirm its historic commitment to...the scholarship of engagement," (Boyer 1997). After graduation, students have accordingly reported that service-learning projects increased their senses of civic responsibility as well as of agency, improving the likelihood that they would seek to volunteer professional community service in the future (Astin et al. 2000).

At the University of Oregon (UO), the Sustainable Cities Institute (SCI) is an interdisciplinary organization that supports education, service, public outreach, and research addressing the design and development of sustainable cities. Each year, the SCI forms partnerships with one or more city governments through the Sustainable City Year Program (SCYP), in which students and faculty from multiple courses collaborate with partner city staff to address ambitious questions and problems of sustainability and livability. These collaborations have resulted in tangible solutions and expanded conversations for the partner cities, previously including Springfield, Redmond, Gresham, Medford, La Pine, Albany, Salem, and others, as well as an expanding group of participating courses in business, planning, geography, law, design, journalism, and other schools and colleges across campus (SCI 2019).

From 2017-19, the Passive Heating Seminar at the University of Oregon collaborated with the SCYP to explore passive solar heating design options for three climatically distinct partner cities: Albany, in the Willamette Valley, with a Mediterranean climate of cool wet winters and warm dry summers; La Pine, in the Cascade mountain range, with a sunny cold climate bordering on subarctic; and Dunes City, on the coast, with a mild cool oceanic climate throughout the year. As well as realizing the service-learning goals above, this effort was intended to promote appreciation in both students and partners of passive solar heating as a viable strategy in environmental design. After the enthusiasm of the 1970s and 8os (e.g. Mazria 1979), passive solar heating came to be viewed skeptically in the U.S., particularly in the Pacific Northwest, because performance of a set of early designs fell far below expectations (Swisher 1984). Decades of low energy prices dampened further experimentation, and by the 2000s, both designer confidence and buyer awareness were found to be low (Garrett and Koontz 2008). Recent research has revealed the underlying causes of the previous performance problems, illuminating the true potential for passive solar heating in cloudy climates (Porteous and MacGregor 2005; Rempel et al. 2013; Rempel et al. 2016; Rempel and Lim 2019), but access to this knowledge and public benefit from it depend on its integration into university coursework and on outreach to the broader community.

The projects in Albany, La Pine, and Dunes City resulted in workable, affordable, and often beautiful schematic designs; they also fulfilled their purposes of inspiring enthusiasm in our partners as well as commitment, imagination, and academic accomplishment in the students. In doing so, they revealed valuable lessons for future courses as explained below.

\section{METHODS}

\section{Course structure}

Each seminar was conducted over an 11-week term. Solar site surveys and meetings with partners were held in Weeks 1-2; climate analysis, thermal comfort and thermal delight discussions, and building heating need evaluations in Weeks 3-4; estimation of optimal glazing tilt angles in Week 5; and cycles of space configuration, thermal mass calculations, movable insulation detailing, and energy modeling from Weeks 6-9, followed by final presentations to partners in Week 11. These were active-learning courses by necessity, involving field measurements, drawing, in-class discussion, calculations, modeling, and presentations of work in progress to classmates.

By the end of the course, successful students were able to (i) describe the priorities and concerns of their community partners; (ii) quantify site and climate conditions; (iii) express design intentions for thermal comfort and thermal delight; (iv) estimate optimal glazing tilts, glazing areas, and thermal mass materials and configurations using hand calculations and material properties; (v) integrate items i-iv into schematic designs and revise them according to partner input; (vi) evaluate performance potential with hand calculations and computational (EnergyPlus) models; and (vii) present their final proposals to their partners in a clear and compelling form. 


\section{City partners and projects}

Given the brief terms and quantitative content of the Passive Heating course, we asked city partners to identify small projects, ideally involving one primary space to be heated. In 2017, the City of Albany expressed interest in designs for park restrooms to prevent water pipe freezing; for a community senior center sunroom; and for a community greenhouse. Because park rentals provide appreciable revenue to the city, and because functional restrooms would allow parks to be reserved for events later in the fall and earlier in the spring, the restrooms were a priority. In 2018, the City of La Pine requested exploration of a new city transit center as well as a community greenhouse and a balcony sunspace prototype for multifamily residences. While the City Center was ambitious programmatically, budget constraints kept it small and unconditioned, allowing it to be a feasible project. In 2019, Dunes City, in turn, requested ideas for passive heating of disaster-relief shelters after learning that it would become a gathering center for refugees following a catastrophic earthquake. The City of Albany supported SCYP staff time and student travel for its projects under the typical SCYP arrangement, while staff time for the small cities of La Pine and Dunes City were supported in part (La Pine) or entirely (Dunes City) by external grant funds.

\section{RESULTS}

\section{Field trips}

Field trips are essential to service learning because students must meet community partners at the sites of interest to understand fully the partners' site-related visions, goals, and concerns, as well as to document conditions of the site that will affect design proposals (Fig. 1). In addition, since field trips involved long travel times and hours outside in inclement weather, they provided early-course bonding experiences that benefited group cohesion and freedom of discussion, supporting structured reflection later in the course. For both of these reasons, such trips were required elements. To prepare for this investment of effort, we found it valuable to visit our community partners several weeks in advance to discuss their ideas and view the sites. These early meetings also established direct rapport between ourselves and our new colleagues, avoiding the common problem of perceived faculty absence or inattention reported by some communities in service-learning projects (Blouin and Perry, 2009).

The greatest obstacle we encountered in field work involved scheduling the trips themselves, given the class, work, and sports commitments of our students. As a result, multiple field trips had to be held each year, and even so, a few students were not able to meet their partners initially. Three years of experience, combined with student suggestions, have therefore given rise to Lesson 1: Before the course begins, plan the field trip with community partners for a weekend day; then, contact students as soon as possible after course registration, or about 4-6 weeks in advance, to alert them to the required trip. In addition, plan a self-directed makeup trip for those who still cannot attend on the scheduled day.
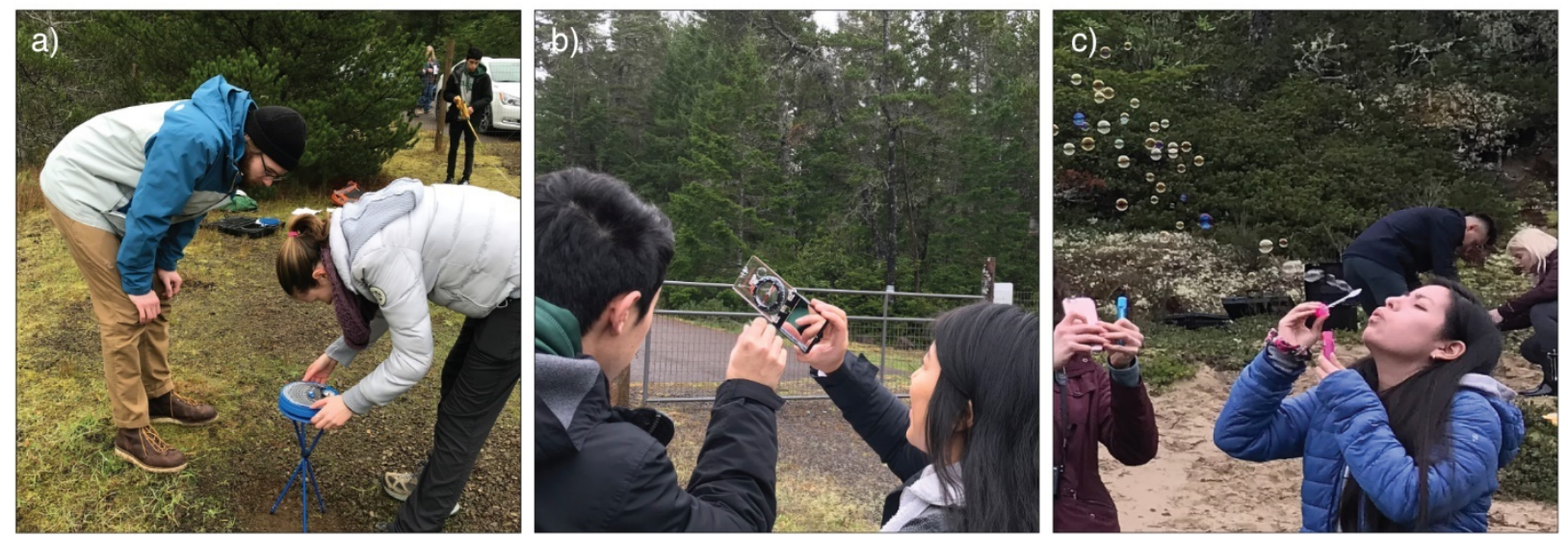

Figure 1. (Dunes City) Solar site surveys include the use of a) solar pathfinders to document site shading; b) inclinometers and field tape measures to establish the heights and positions of site shading elements for use in computational models; and c) airflow bubbles to document prevailing wind directions on the site. 


\section{Schematic design}

Soon after the field work, students assembled site measurements into plan and section drawings that documented significant views, surface materials, topography, and vegetation. These drawings helped students appreciate site challenges immediately, such as the desired position of a community sunroom on the north side of the senior center in Albany, combined with the need of the sunroom to provide clear views to the river on the north side as well (Fig. 2).
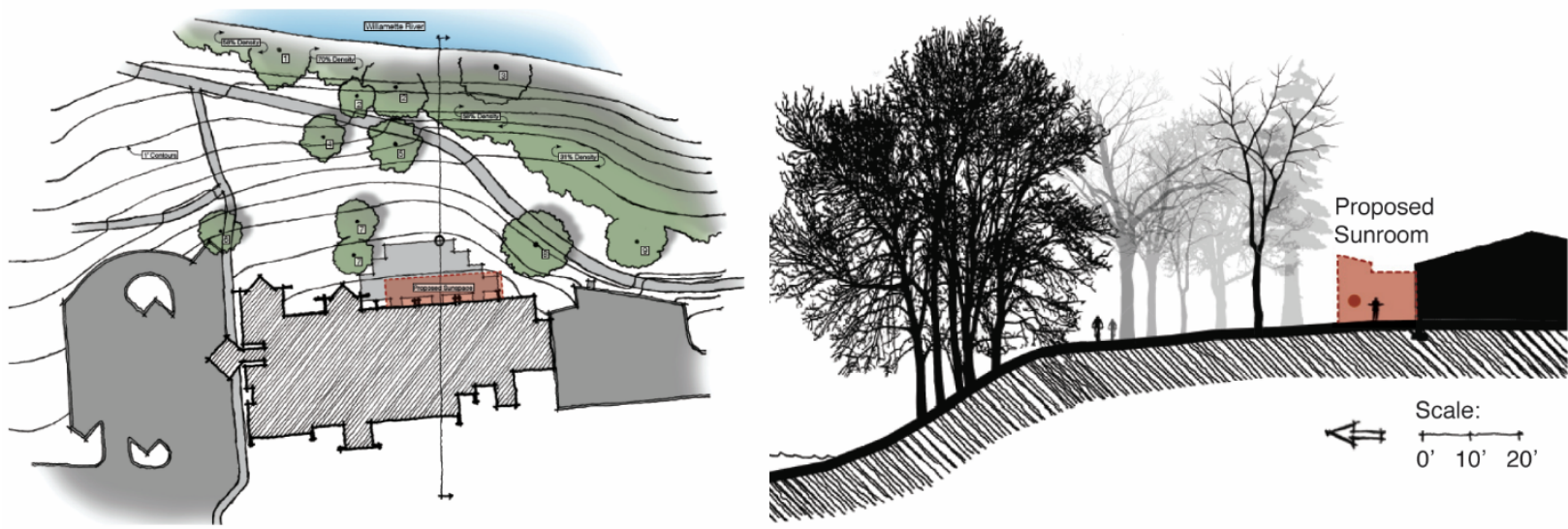

Figure 2. (Albany) Following site surveys, students documented topography, surface materials, tree heights and positions, buildings, views, and preliminary design ideas in site plans and sections. The project above explored community center sunspace designs that collected southern sun while providing views of the river on the north.

These drawings also provided a visual context with which to interpret site shading diagrams, or "masks", acquired with solar pathfinders. A solar pathfinder placed at a position of interest (Fig. 1a, above) reflects all horizon objects onto a sun-path diagram for that spot, showing the hours of the year during which it is shaded by trees or buildings. For projects with flexibility in positioning, such as the park restrooms and greenhouse in Albany and the La Pine City Center, students combined these masks (gray forms in Fig. 3, upper panels) with hourly solar radiation intensity data acquired from weather files (colored sectors). The resulting diagrams allowed them to identify positions on the site at which the solar resource was least obstructed by site shading, as well as to determine whether a non-south orientation might be most favorable. In Albany, such an investigation of three positions on the community greenhouse site that were expected to have favorable vehicle access resulted in a clear choice of location and orientation (Fig. 3).

Finding the optimal tilt for solar-collecting glass was the next step. To do this, students first estimated each building type's monthly heating energy needs based on expected envelope U-values and infiltration rates, expected outdoor temperatures, and desired indoor temperature ranges. Such heating needs are shown by a thin line in Fig. 4a and by vertical bars in Figs. 4b and 4c. Because most space types (greenhouses, residential spaces, park restrooms, shelters) were expected to be unconditioned, the ASHRAE 55-2017 Adaptive Comfort Zone primarily guided choices of indoor temperature ranges. Next, students found the solar radiation incident on surfaces of $0-90^{\circ}$ tilt, at $10^{\circ}$ increments, during each month of the heating season, from source data provided by Rempel (in press). Optimal tilts were then selected as those that intercepted the greatest solar energy over an area realistic for the building during the heating season, up to the level of heating need. This changed two common practices in passive heating education that were based on work of the early 1980 (Balcomb 1983): first, it incorporated recent research documenting the importance of tilted collector area compared to projected vertical area in cloudy climates (Rempel et al. 2013), and second, it emphasized the total quantity of solar energy available to be sought, or the "net solar heating resource" (shaded areas in the right panel of Fig. 4a), rather than the fraction of heating energy that might be offset by solar energy, or the Solar Savings Fraction.

The glass sizing process then balanced considerations of solar heat gain with the costs of movable insulation, since each additional unit area of solar-collecting glazing would meet a smaller proportion of the heating need but would require as much movable insulation and shading as any other unit (Fig. 4). 


\section{Test Location 1}
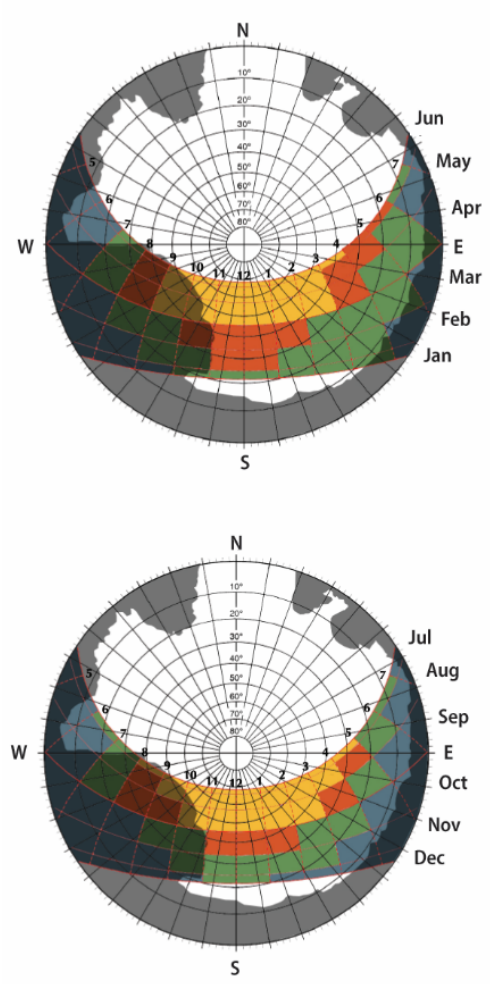

Test Location 2
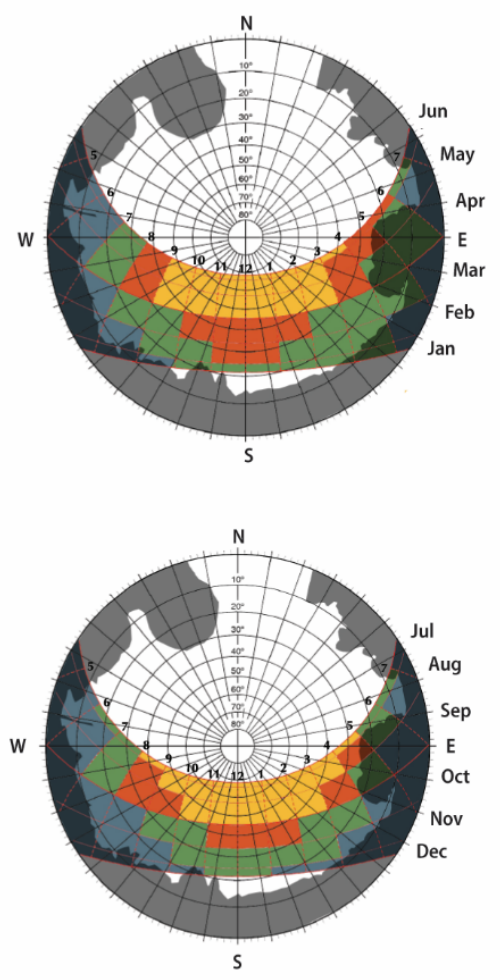

\section{Greenhouse Location}

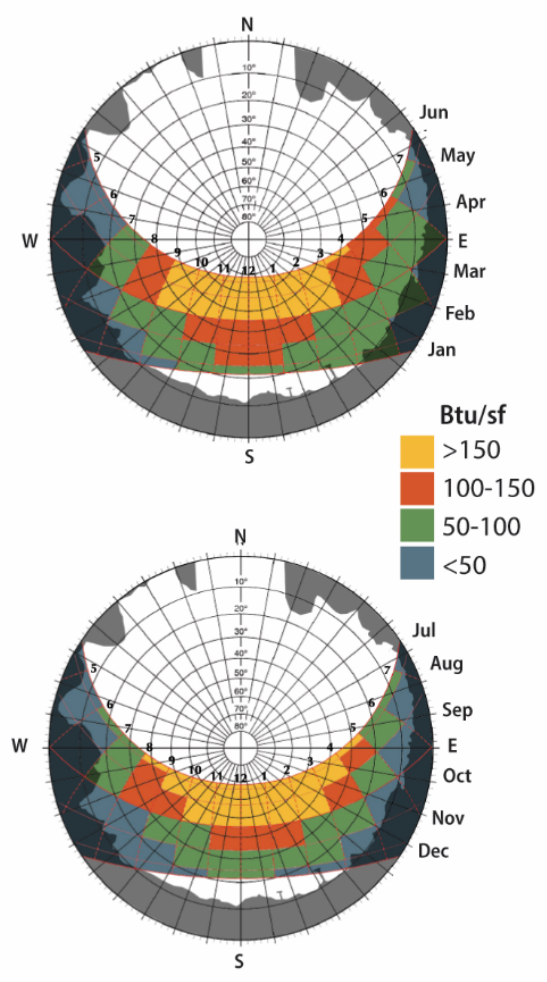

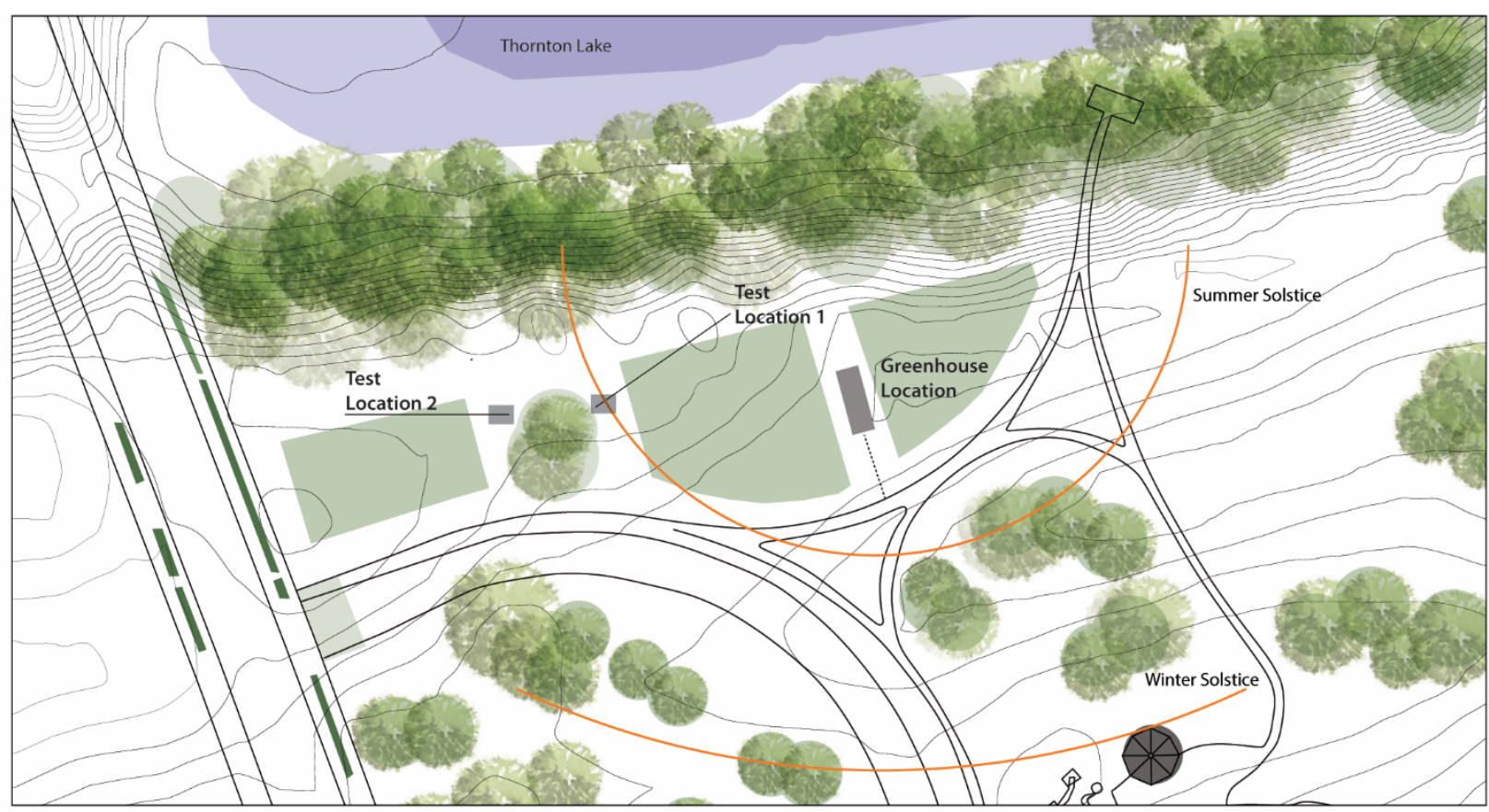

Figure 3. (Albany) To find specific sites and orientations for their projects, students used site shading masks (upper panels, gray areas in each diagram) obtained from pathfinder photos that showed the hours of the year each site would be shaded. Visual combination of these masks with estimates of hourly annual solar radiation intensity (yellow, red, and green) from local weather files guided this group in recommending a specific site and orientation for a community greenhouse (below), to which they added a proposal for new roads, paths, and outdoor gardens. 


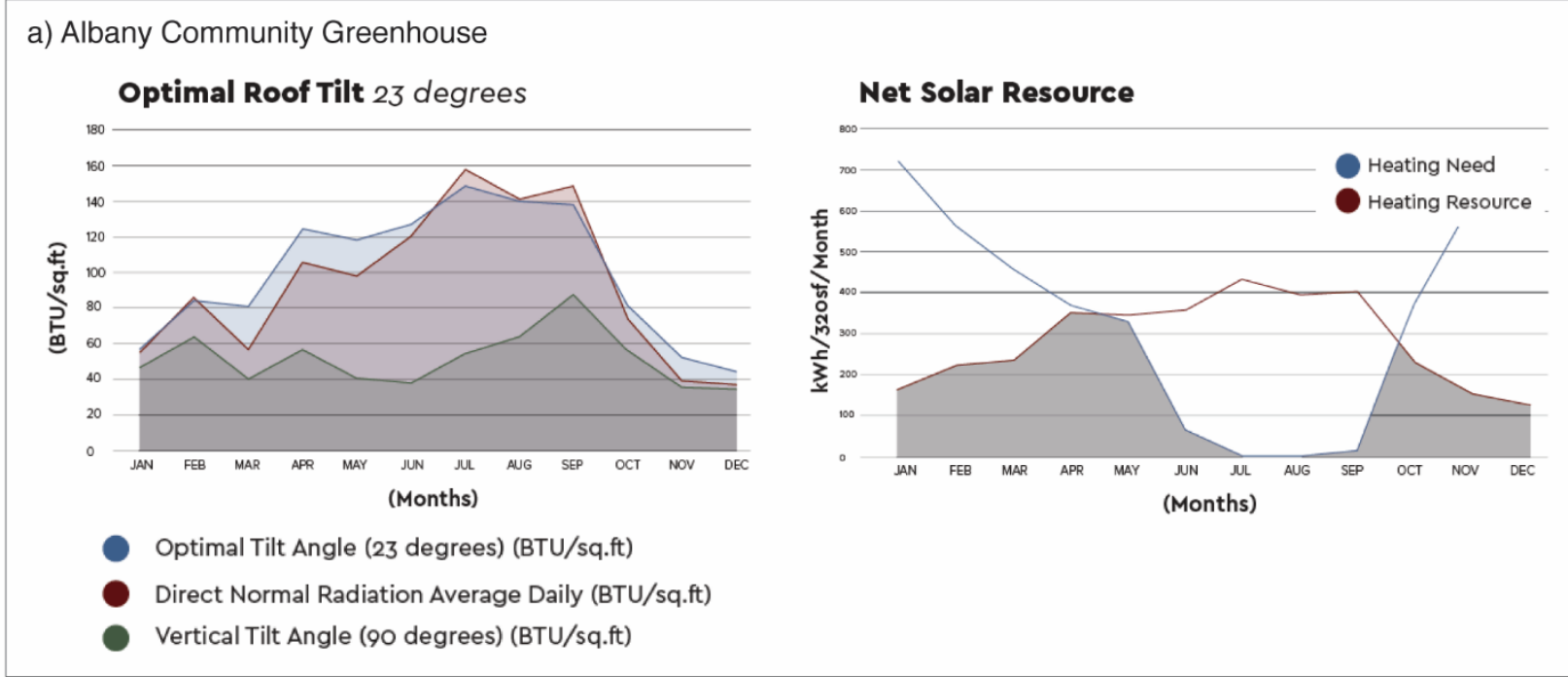

b) La Pine Balcony Sunspace
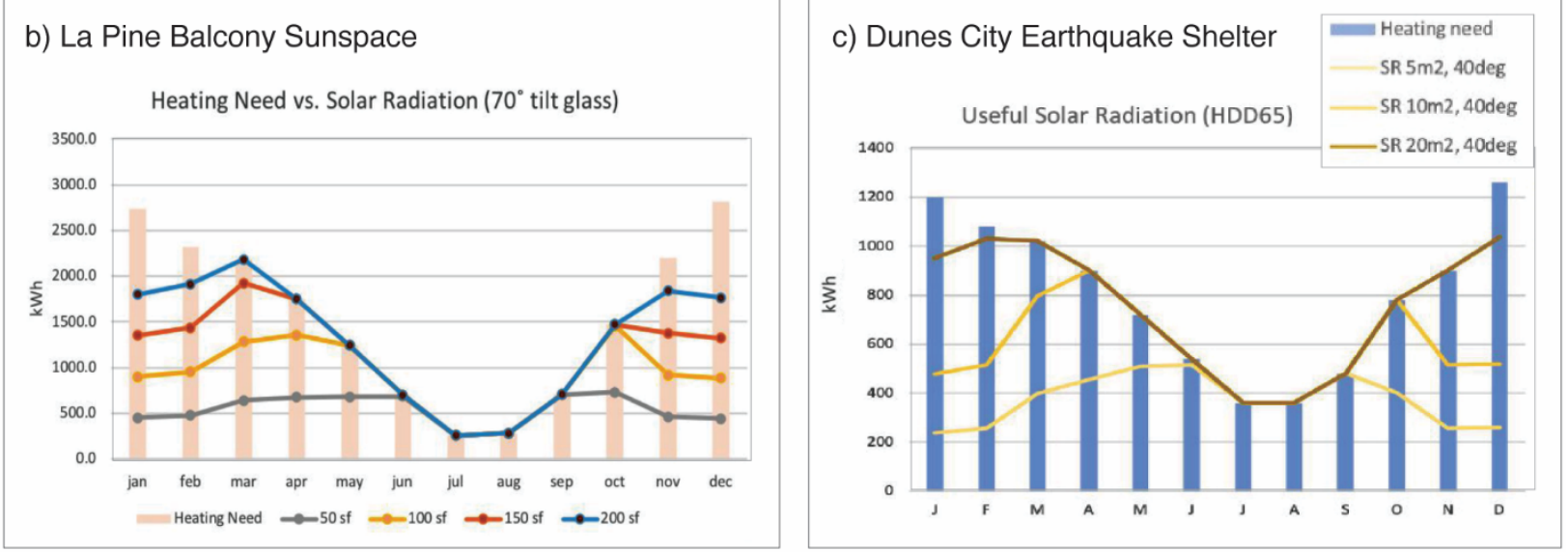

Figure 4. (a) Albany, (b) La Pine, (c) Dunes City. To find optimal glass tilts and areas, students first evaluated each heating season in monthly heating degree-days and estimated their buildings' heating energy needs, expressing these results in monthly heating energy needed (Btu or kWh) per HDD (thin line in the right panel of a); vertical bars in b) and c)). Comparison with solar energy received during the heating season by surfaces of $0-90^{\circ}$ tilt, at $10^{\circ}$ increments, then revealed the angle that received the most solar radiation when heat was needed. Use of that tilt revealed the net solar heating resource (right panel of a)). Next, comparison of radiation received by various collector areas, and its coincidence with need, allowed the final area to be chosen (solid lines in b) and c)). Note the climate- and buildingspecific tilts of $23^{\circ}$ for the Albany greenhouse, $70^{\circ}$ for La Pine residences, and $40^{\circ}$ for Dunes City shelters.

Next, students developed conceptual designs that incorporated their partners' ideas regarding program and spatial experience as well as site conditions, solar radiation intensity patterns, building heat loss estimates, thermal comfort intents, and preliminary thermal mass calculations. One Albany park restroom combined a direct-gain approach, using an optimal tilt and area found by the process above, with movable insulation that doubled as summer shading; an elevated ramp accommodated seasonal park flooding (Fig. 5a). An Albany community sunroom, in turn, provided views to the north but primarily collected solar radiation using steeper glazing on the south, with operable skylights reflecting attention to summer cooling (Fig. 5b). In sunnier La Pine, optimal tilts for balcony sunspaces were steep, at $70^{\circ}$, and the lower balcony was extended beyond the upper to maintain this optimum (Fig. 5c). Again, movable insulation doubled as summer shading and vents provided passive cooling. A City Center scheme in La Pine, in contrast, elected all-vertical glazing in a high-mass direct-gain approach (Fig. $5 \mathrm{~d}$ ). In the cloudier, forested Dunes City site, solar gain was useful nearly all year, and a row of sunspaces was supported by bedrock anchors to ensure that the structure would survive to meet its time of need (Fig. 5e). 


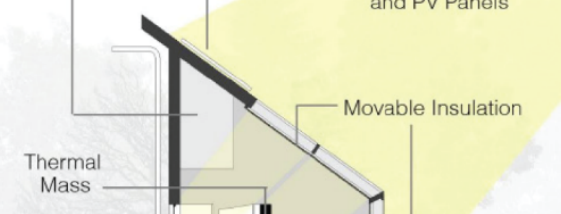

EXTERIOR WALL

CONSTRUCTION

Siding Wood- Bevel 13 by $200 \mathrm{~mm}$

$50 \mathrm{~mm}$ Insulation Board

$154 \mathrm{~mm}$ Batt Insulation

Air Space

20mm Gypsum Board$$
\text { Mass }
$$

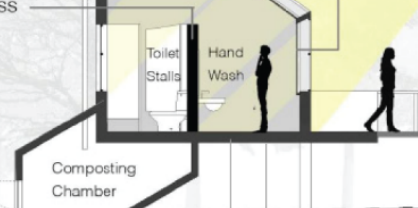

$\beta$

b) Albany community sunroom
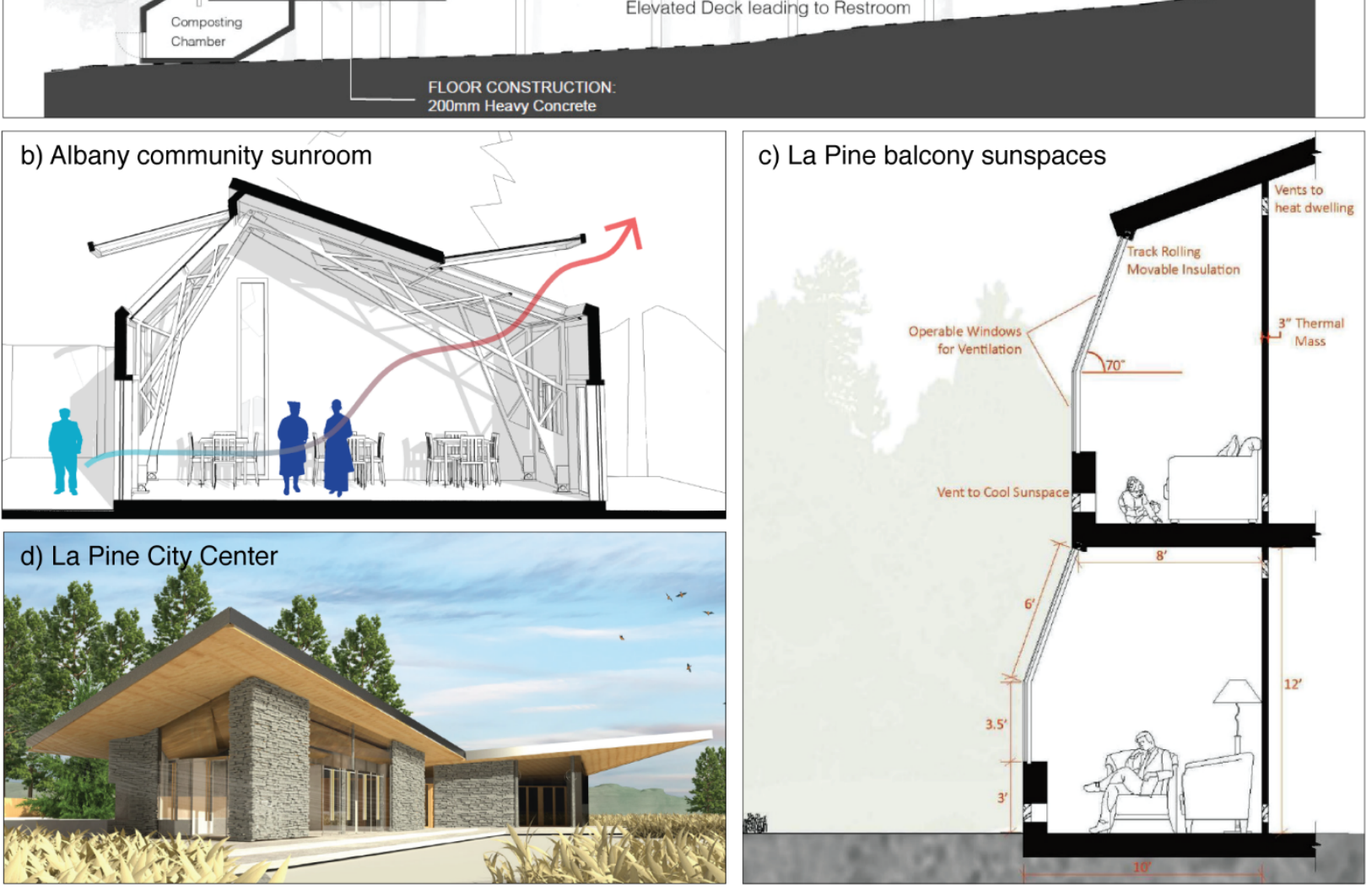

FLOOR CONSTRUCTION

Elevated Deck leading to Restroom

e) Dunes City earthquake shelter

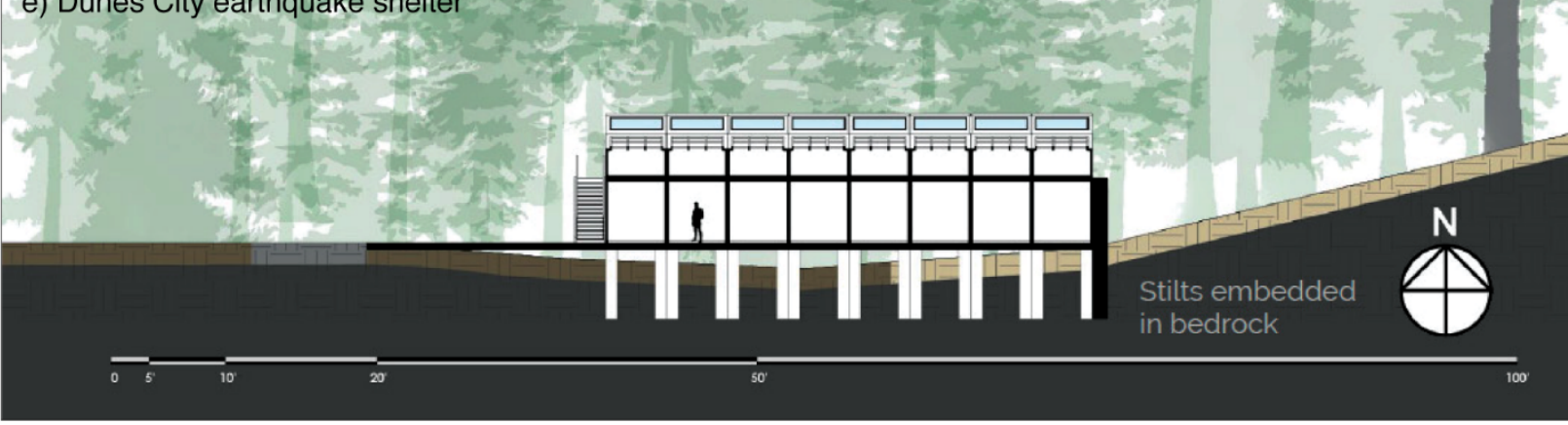

Figure 5. The work of Figs. 1-4 led to these conceptual designs for Albany (a, b), La Pine (c, d), and Dunes City (e). 


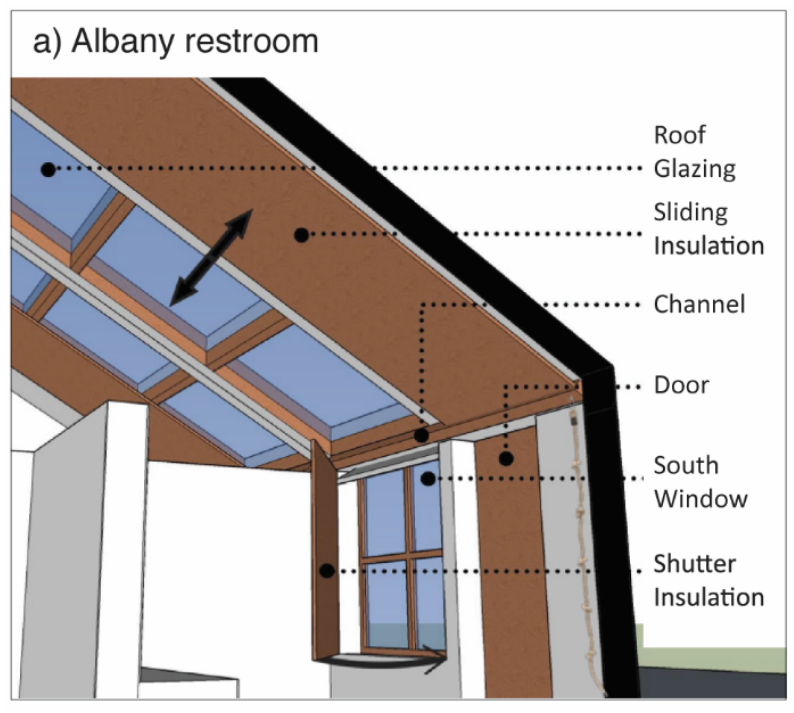

b) Dunes City shelter

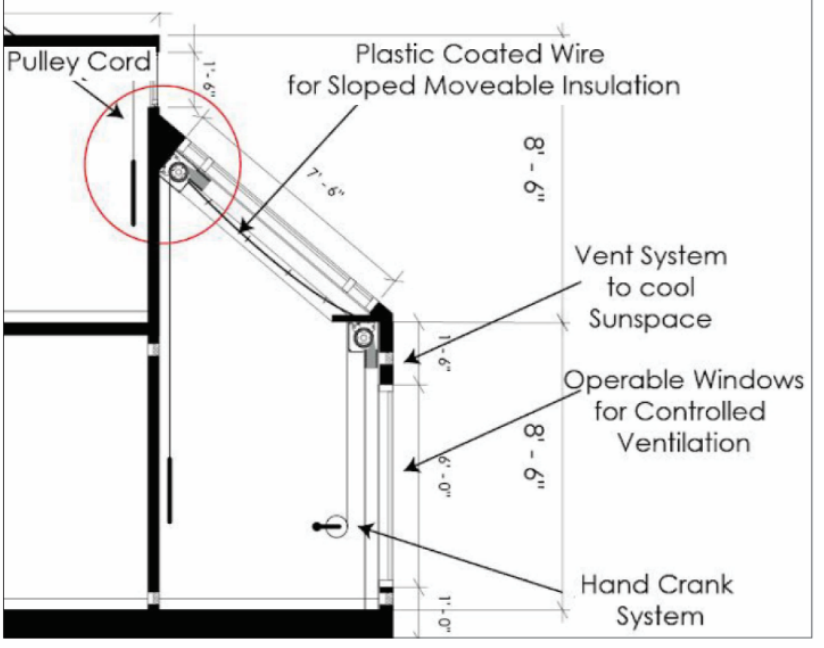

c) Albany Community Center sunroom
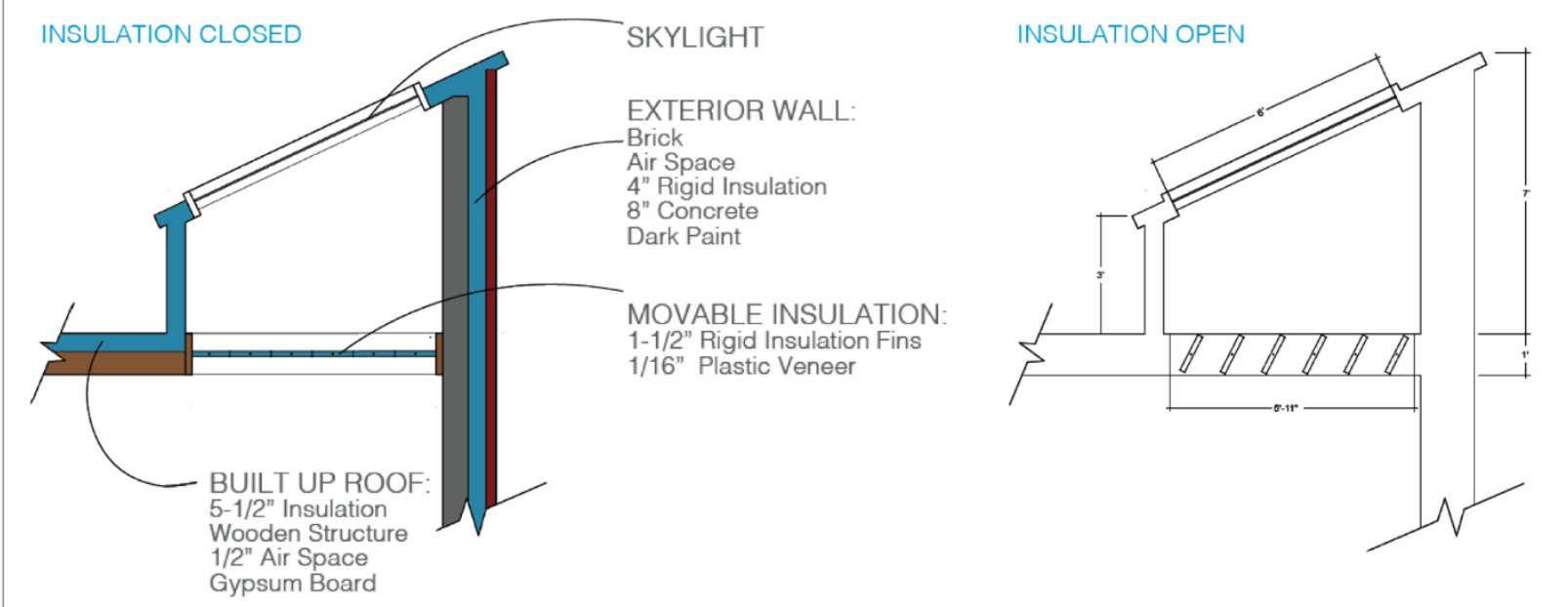

Figure 6. Movable insulation schemes were added next; above are shown a) durable rigid sliding panels and shutters (Albany); b) rolling curtains operated by pulleys and cranks (Dunes City) and (c) rotating slats with antiglare utility (Albany). Operability schedules for movable insulation were developed in EnergyPlus.

Near the end of the term, given the necessity in these climates, movable insulation details and schedules were developed as well (Fig. 6), emphasizing operability, convenience, and effectiveness. In most cases, the movable insulation was expected to serve as summer shading as well, since virtually all passive solar spaces require shading (as well as natural ventilation) for summer de-activation.

Informal discussions with partners were frequent throughout the conceptual design phase, but designs were changing too rapidly, in order to meet performance goals, for the partners to receive understandable midterm drawings to review. We also found that the brief time available and the desire to create excellent proposals led students to focus on specific applications of quantitative elements to the detriment of more general understanding. To address this problem, students suggested Lesson 2: Incorporate low-pressure activities that investigate course topics beyond the immediate projects. In subsequent years these have included problem sets, short collaborative quizzes, and a model competition. Students have since reported that the collaborative quizzes, in which pairs discuss and solve problems together, have been most effective in developing their fluency with physical concepts (e.g. material properties; heat transfer), while monitoring the outdoor performance of competition models was most effective in developing intuition. 


\section{Performance}

Because passive solar heating designs must perform well to support future adoption, and because EnergyPlus models are able to simulate this performance well (e.g. Rempel et al. 2013), building energy modeling was required (Fig. 7). Fortunately, the modularity of EnergyPlus allowed students to learn a limited, well-defined set of skills (creating thermal zones and site shading; specifying material thermal and optical properties, constructions, internal heat gains, and infiltration rates; specifying and scheduling movable insulation; requesting output variables) without the complexity of simulating mechanical HVAC, water, advanced lighting, or control systems. Models were also restricted to one or two thermal zones. To accommodate the effort required, we found that instruction needed to begin early in the term with simple practice models. Digital tutorials describing program installation and showing command locations, as well as small weekly assignments, assisted the learning process greatly, and email support allowed work to progress without delays for in-person meetings. Once students were able to graph and interpret output data from the practice models, they were ready to modify or add a manageable number of elements each week. One assignment, for example, involved (i) graphing window heat gain/loss patterns over a week of interest, (ii) describing performance problems found, (iii) proposing two solutions involving only glazing materials and movable insulation, (iv) implementing them individually, requiring modification of only six objects, and (v) evaluating the results. By the end, as a result, most models had been thoroughly checked by the instructor, and their results realistically represented the performance potentials of their projects.
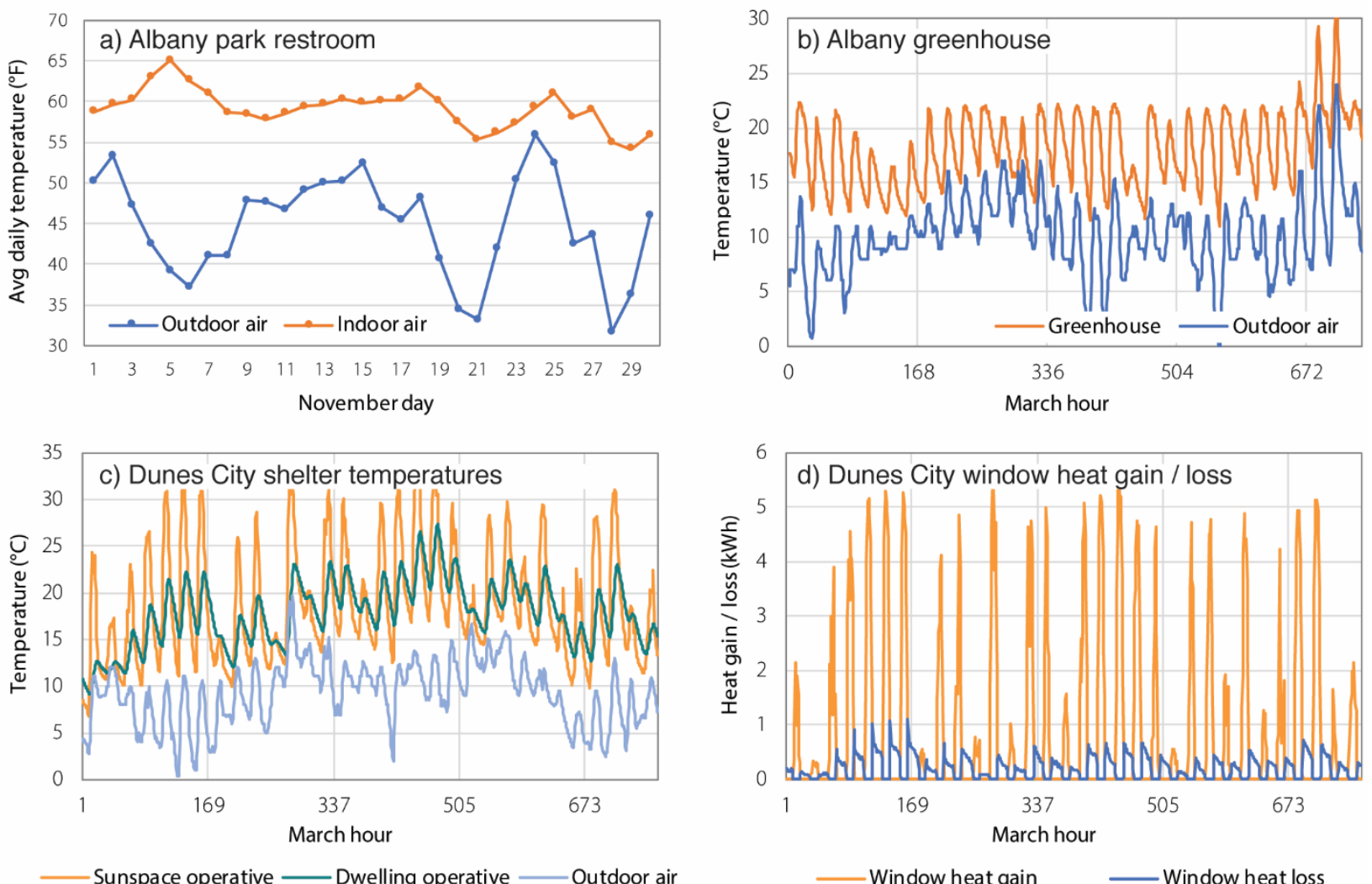

Sunspace operative ——Dwelling operative —— Outdoor air

Figure 7. Throughout the term, students monitored the performance of their designs with the building energy simulator EnergyPlus. Starting with estimates made by hand calculations, they used models to revise tilts and areas of solar-collecting glazing; to improve thermal mass performance by varying material, area, and thickness; and to improve movable insulation performance by varying materials and schedules. Above, model-predicted indoor vs. outdoor temperatures are shown for (a) an Albany park restroom, (b) the Albany community greenhouse, and (c) a Dunes City earthquake shelter and its accompanying sunspace, each documenting appreciable solar heating potential. In addition, window heat gain/loss patterns used for development of nighttime movable insulation materials and schedules are shown for (d) the same Dunes City shelter, illustrating its predicted effectiveness. 
One challenge students found, as expected, was the temptation to adjust model parameters haphazardly, risking their ability to develop reliable intuition. To help them resist this, we emphasized the use of hand calculations and physical reasoning to provide starting points for input values (e.g. mass thickness; skylight solar heat gain coefficients). We also emphasized the use of output data to reveal thermal processes and patterns, and thereby to inform thoughtful modification, by requiring students to interpret their results and explain the reasons for their changes at each step. A second challenge we found was that, while most students welcomed the chance to learn EnergyPlus, some preferred to rely on others' work where possible. The understandable objections of group members necessitated Lesson 3: Establish metrics for group accountability that clearly explain the individual component of each learning outcome. In addition, after the first year, all modeling assignments were individually submitted and credited. Finally, students found that a third significant challenge was the communication of quantitative graphic information. Because clear documentation was so important in explaining results to our partners, we also adopted Lesson 4: Plan several cycles of informal peer reviews of quantitative content, in which groups explain their graphs to one another, during the last several weeks of the term.

\section{Structured reflection}

Our collaborators each year were energetic, articulate people who were thrilled to be our partners and were highly responsive to student ideas, questions, and requests for information. Fortunately, however, some realism did arise in student-partner interactions. On occasion, students heard collaborators express desires that seemed to contradict earlier positions; received site drawings that seemed incomplete, incorrect, or incompatible with other information; and read community stakeholder documents suggesting the intent to exclude some citizens from the future designs. Once, students found their preliminary drawings merged with those of a city engineer in a way counter to their intent. And often, collaborators questioned the students' final designs closely, expressing concerns and sometimes doubts that were not easy to address, and pressing them to explain unclear graphics or statements. These moments were disconcerting for the students, they admitted, but most considered them to be important indications of the partners' interest and commitment as well as of broader themes they would encounter in the future. The importance of these experiences and time for their processing is recognized by Lesson 5: Provide time during the course, and after final presentations, for students to discuss and reflect on their experiences, their partnerships, and their roles within them, including strategies for future work.

\section{Epilogue}

After each term, the SCYP edits, interprets, and compiles student projects into bound reports for city partners. In part, this reflects Lesson 6: At the end, clarify the strengths and weaknesses of each project, as well as general recommendations emerging from the group of projects, so that partners can make wellinformed decisions. In addition, we stress Lesson 7: be available for questions and discussion after the term. To date, projects for Albany have facilitated fundraising efforts for park restroom replacement; the City Center for La Pine is undergoing design development; further research into the balcony sunspaces initiated in La Pine has been funded by the National Science Foundation; and Dunes City has recently received its final report.

\section{ACKNOWLEDGEMENTS}

We sincerely thank the numerous students who contributed to the work shown for both their designs and for their enthusiastic participation in the course. These include (Albany 2017): Kayla Bundy, Travis Blunt, Jordan Frazin, Kelli Kimura, Chazandra Kern, Zhengxian Jin, Ashley Kopetzky, Dristi Mandahar, Scott McClelland, Danielle Pomeroy, Isabel Rivera, Shradhan Shrivastav, Lindsey Suprenant, Hieu Vo, Kayla Zander; (La Pine 2018): Rowan Atherley, Philippa Bailey, Austin Daich, Jared Dukes, Achyuthan Ramaswamy, and Zoe Walker-Aparicio; and (Dunes City 2019): Virginia Bailey, Francisco Martinez, Denise Blankenberger, Hannah McKay, Lindsey Naganuma, Bryce Shortall, and Estefania Valdivia.

This work was supported in part by National Science Foundation grant CBET-1804218: "Climateresponsive Design and Control Strategies for Affordable Multi-Family Residences". La Pine and Dunes City efforts were supported by The Ford Family and JPB Foundations, respectively. 


\section{REFERENCES}

Astin, Alexander W., Vogelgesang, Lori J., Ikeda, Elaine K., and Yee, Jennifer A. 2000. "How Service Learning Affects Students". Higher Education. Paper 144. Accessed June 1, 2019. http://digitalcommons.unomaha.edu/slcehighered/144.

Balcomb, J. Douglas. 1983. Passive Solar Design Handbook. American Solar Energy Society, Golden CO.

Blouin, David D. and Evelyn M. Perry. 2009. "Whom does service learning really serve? Communitybased organizations' perspectives on service learning." Teaching Sociology 37, no. 2: 120-135.

Boyer, Ernest L. 1997. "The scholarship of engagement." Journal of Public Service and Outreach 1:11-20.

Bringle, Robert G. and Julie A. Hatcher. 1996. "Implementing service learning in higher education." The Journal of Higher Education 67, no. 2: 221-239.

Bringle, Robert G. and Julie A. Hatcher. 2000. "Institutionalization of service learning in higher education." The Journal of Higher Education 71, no. 3: 273-290.

Garrett, Vicki, and Tomas M. Koontz. 2008. "Breaking the cycle: Producer and consumer perspectives on the non-adoption of passive solar housing in the US." Energy Policy 36, no. 4: 1551-1566.

Mazria, Edward. 1979. Passive solar energy book, Rodale Press, Emmaus PA.

Porteous, C. and A. W. K. MacGregor. 2005. "Latitude myths challenged." Solar Architecture in Cool Climates, Earthscan Press, London.

Rempel, Alexandra R. In press. "Passive Heating". In: Grondzik, W.T. and Kwok, A.G., Eds., Mechanical and Electrical Equipment for Buildings, $13^{\text {th }}$ Edition. John Wiley and Sons, New York.

Rempel, Alexandra R. and Serena Lim. 2019. "Numerical optimization of integrated passive heating and cooling systems yields simple protocols for building energy decarbonization." Science and Technology for the Built Environment just-accepted: 1-17. DOI: 10.1080/23744731.2019.1620578.

Rempel, Alexandra R., Alan W. Rempel, Katharine Cashman, Ken R. Gates, Catherine Page, and Barbara Shaw. 2013. "Interpretation of passive solar field data with EnergyPlus models: Un-conventional wisdom from four sunspaces in Eugene, Oregon." Building and Environment 60: 158-172.

Rempel, Alexandra R., Alan W. Rempel, Ken R. Gates, and Barbara Shaw. 2016. "Climate-responsive thermal mass design for Pacific Northwest sunspaces." Renewable Energy 85: 981-993.

Sandy, Marie and Barbara A. Holland. 2006. "Different worlds and common ground: Community partner perspectives on campus-community partnerships." Michigan Journal of Community Service Learning 13, no. 1: 30-43.

(SCI) Sustainable Cities Institute. 2019. "Sustainable City Year Program is Transforming Oregon Cities Large and Small.” Accessed June 28, 2019. https://sci.uoregon.edu/sustainable-city-year-program-o.

Sedlak, Carol A., Margaret O. Doheny, Nancy Panthofer, and Ella Anaya. 2003. "Critical thinking in students' service-learning experiences." College Teaching 51, no. 3: 99-104.

Sletto, Bjørn. 2010. "Educating reflective practitioners: Learning to embrace the unexpected through service learning." Journal of Planning Education and Research 29, no.4: 403-415.

Swisher, Joel. 1984. "Passive Solar Performance: Results of 1982-1983 Class B Results." Washington, US GPO, SERI/SP-271-2362. 